\title{
Occurrence of Escherichia coli 0157:H7 in Faecal Sample of Sheep and Goats in North East Karnataka
}

\author{
Pralhad*, Basavaraj Awati, B.K. Ramesh, N.A. Patil, Pradeep Kumar, B. Jaganath Rao, \\ P.T. Vinay, K.C. Mallinath, Arun Kharate, P. Suryakanth and M. Revappayya \\ Department of Veterinary Microbiology, Veterinary College, Bidar-585401, India \\ *Corresponding author
}

\begin{tabular}{|l|}
\hline K e y w o r d s \\
$\begin{array}{l}\text { E. coli O157: H7, sheep } \\
\text { and goats, latex } \\
\text { agglutination test, North } \\
\text { East Karnataka }\end{array}$ \\
\hline Article Info \\
\hline $\begin{array}{l}\text { Accepted: } \\
\text { 14 November } 2018 \\
\text { Available Online: } \\
\text { 10 December } 2018\end{array}$ \\
\hline
\end{tabular}

\section{Introduction}

The E. coli which produce shiga toxins (stx) have been referred as Shiga toxin-producing E. coli (STEC). A subgroup of STEC causes watery diarrhoea in humans which can progress to haemorrhagic colitis and potential systemic complications due to the action of stx (Kaper et al., 2004).

These are referred to as EHEC. About 200 EHEC serotypes have been isolated from
E. coli $\mathrm{O} 157: \mathrm{H} 7$ is an emerging food borne pathogen having zoonotic importance. Though the primary reservoir of the serotype is cattle; sheep and goats are also considered as main reservoir for $E$. coli $\mathrm{O} 157: \mathrm{H} 7$, which act as asymptomatic carriers. Conventional cultural and biochemical methods are time consuming to detect E. coli O157:H7 in food borne outbreaks and have less specificity and sensitivity. Latex agglutination test (LAT) tends to be specific, more rapid and reliable. In the present study, faecal samples collected from sheep $(n=517)$ and goats $(n=450)$ from different farms across North Eastern Karnataka during June 2016 to August 2017 were analysed. The samples were processed and analysed for the cultural isolation, biochemical characterisation and latex agglutination test. In this study, LAT was taken as confirmative diagnostic test and the results obtained by cultural isolation and biochemical characterisation were compared with that of LAT to estimate the sensitivity and the specificity. The percent of sheep and goats that showed shedding of E. coli $\mathrm{O} 157$ in the faeces was $3.67 \%$ (19 out of 517 ) and $2.88 \%$ (13 out of $450)$ respectively. The results obtained show that LAT is a rapid, highly sensitive, speciesspecific and reliable method for the detection of the pathogenic E. coli $\mathrm{O} 157: \mathrm{H} 7$ and could be used for identification and molecular characterisation of $E$. coli $\mathrm{O} 157: \mathrm{H} 7$ in suspected food and water borne outbreaks, disease investigations and routine analysis. 
E. coli $\mathrm{O} 157: \mathrm{H} 7$ is a zoonotic bacterium that causes human disease. It is mainly pathogenic to humans (Soderlund et al., 2012) does not cause any clinical disease except diarrhoea (in rare occasions) in cattle and other animals due to the difference in distribution of $\mathrm{Gb} 3$ receptors between cattle and humans. The infections by $E$. coli $\mathrm{O} 157: \mathrm{H} 7$ have been reported of increasing frequency from all parts of the world in the form of food poisoning outbreaks (Jo et al., 2004).

E.coli $\mathrm{O} 157: \mathrm{H} 7$ is one of the most important food-borne pathogens, causing diarrhoea, hemorrhagic colitis and haemolytic-uremic syndrome in humans worldwide. Important reservoirs of pathogenic E. coli $\mathrm{O} 157: \mathrm{H} 7$ in the environment have been ruminants, particularly cattle, sheep and goats which are asymptomatic carriers. These asymptomatic carriers normally shed the organism in faeces contaminating soil and surface waters. Transmission to people occurs primarily via ingestion of inadequately processed contaminated food or water and less frequently through contact with manure, contaminated soil and water or animals and infected people. Cattle are the major reservoirs of $E$. coli $\mathrm{O} 157: \mathrm{H} 7$ followed by sheep and goats. Because of the severity of illnesses and the apparent low infective dose (Bach et al., 2002), E. coli $\mathrm{O} 157: \mathrm{H} 7$ is considered one of the most serious of known food borne pathogens (Blanco et al., 2003). The authority of the Federal Meat Inspection Act, FSIS declared E. coli $\mathrm{O} 157: \mathrm{H} 7$ as an adulterant in raw ground beef and enforced "zero tolerance" (USDA-FSIS, 2015).

The pathogen is carried in the intestinal tract and excreted in faeces. The entry of the bacilli into the meat by carcass contamination can be through transfer of pathogen from the intestines during the evisceration procedure, from the hide onto the carcass during flaying, contaminated equipment and tools used during flaying, contaminated operator's hands or contaminated dust particles and water droplets spread by aerosols generated in the production process (Narvaez-Bravo et al., 2013). Consumption of raw or undercooked foods, especially undercooked minced beef and meat has been found to be the most common means of transmission (Chapman et al., 2001).

In India, there is paucity of information on prevalence of E. coli $\mathrm{O} 157: \mathrm{H} 7$ in sheep and goats. With this background, the present research work was undertaken to isolate and confirm E. coli $\mathrm{O} 157: \mathrm{H} 7$ from faecal samples of sheep and goats by cultural identification, and biochemical characterisation. Further confirmation was done by latex agglutination test.

\section{Materials and Methods}

\section{Study area and animals}

The study was carried out during from June 2016 to August 2017 and faecal samples were collected from sheep $(n=517)$ and goats $(n=450)$ from different farms across North Eastern Karnataka.

\section{Sample collections}

The faecal samples were collected in sterile vials directly from rectum using sterile cotton swab sticks (Hi Media, Mumbai, India). They were labelled properly and transported to laboratory in thermo-cool container jacketed with ice packs. The samples were processed and analyzed for the isolation of E. coli O157:H7 within 24 hours.

\section{Cultural isolation and biochemical characterisation of $E$. coli $0157: \mathrm{H} 7$ from faecal samples}

One grams of each faecal sample was inoculated into $9 \mathrm{ml}$ (1:9 ratio) modified 
tryptone soya broth (mTSB) supplemented with novobiocin and incubated overnight at $37^{\circ} \mathrm{C}$ for 24 hours. A loopful of inoculum from the enrichment medium was inoculated onto selective isolation media Sorbitol MacConkey agar supplemented with cefixime $(0.025 \mathrm{mg})$ and potassium tellurite $(1.25 \mathrm{mg})$ (CT-SMAC). The agar plate was incubated for $24 \mathrm{hrs}$ at $37^{\circ} \mathrm{C}$. Growth of typical small, circular colourless colonies (sorbitol negative) with a smoky centre and measuring 1-2 $\mathrm{mm}$ in diameter indicated E. coli $\mathrm{O} 157: \mathrm{H} 7$ as shown in Fig 1.

The suspected E. coli O157:H7 isolates showed Gram negative character indicated by pink coloured coccobacilli (took counter stain safranin) under the $100 x$ oil immersion microscope. When further inoculated on EMB agar differential media, the suspected E. coli O157:H7 isolates produced black centered colonies with metallic sheen on EMB agar as shown in Fig 2.

Further, isolated colonies were subjected to various biochemical tests such as IMViC (Indole, Methyl Red, Voges Proskeur and Citrate utilization) tests, Glucuronidase test, Nitrate reduction test, Lysine utilization test, ONPG test and sugar fermentation tests (Lactose, Glucose, Sucrose, and Sorbitol tests) using KB010 E. coli identification kit (Hi Media, Mumbai, India). The isolates which showed positive reaction for Indole test, Methyl red test, Glucuronidase test, Nitrate reduction test, Lysine utilization test, ONPG test and sugar fermentation tests (Lactose, Glucose, Sucrose) and negative for VogesProskauer test, Citrate utilization test and Sorbitol fermentation tests were presumed as positive for $E$. coli $\mathrm{O} 157: \mathrm{H} 7$ as shown in Figure 3.

For the confirmation of samples found positive for $E$. coli $\mathrm{O} 157: \mathrm{H} 7$ by cultural isolation and biochemical tests, the isolated colonies on CT-SMAC agar were tested for the presence of $\mathrm{O} 157$ and $\mathrm{H} 7$ antigens by latex agglutination using Wellcolex ${ }^{\circledR} \quad E$. coli O157:H7 kit as shown in Fig 4.

\section{Results and Discussion}

Domestic and wild animals are source of $E$. coli $\mathrm{O} 157: \mathrm{H} 7$ but the major animal carriers are healthy domesticated ruminants, primarily cattle, sheep and goats which act as asymptomatic carriers (La Ragione et al., 2009). These asymptomatic carriers normally shed the organism in faeces contaminating soil and surface water. Considering the zoonotic importance of $E$. coli O157: H7, rapid method for its detection are important to identify the source of outbreak and to assure public safety.

In India too, there could be food borne outbreaks from this pathogen as people consume meat and meat products. However, systematic diagnosis of food borne outbreaks in India is a rare phenomenon. Few scientists have worked on the incidence of this pathogen in various livestock products (Bindu and Krishnaiah 2010), human patients (Khan et al., 2002a; Khan et al., 2002b) and environmental samples (Hazarika et al., 2007).

In the present study faecal samples were inoculated onto modified Tryptone Soya Broth (mTSB). Tryptone Soya Broth as an enrichment medium specifically for $E$. coli O157:H7 has been recommended by ISO committee. Several researchers from India and other countries have used Tryptone Soya Broth supplemented with novobiocin as enrichment medium for $E$. coli O157:H7 (Bindu and Krishnaiah, 2010; Puttalingamma and Harshvardhan, 2013).

E. coli $\mathrm{O} 157: \mathrm{H} 7$ rapidly ferments lactose and is indistinguishable from most other $E$. coli on traditional lactose containing media. However, E. coli O157:H7 cannot ferment sorbitol 
within 24 hrs, while $90 \%$ of $E$. coli can. This character was used as a criterion for differentiating it from other E. coli (Adamu et al., 2014). Centers for Disease Control and Prevention also recommends SorbitolMacConkey as selective indicator media for $E$. coli O157:H7 (CDC, 2009). In addition, Orth et al., (2007) showed the resistance of E. coli O157:H7 for tellurite and therefore grows often in concentration that inhibits most other E. coli.

In the present study, inoculum from the enrichment medium was inoculated onto CTSMAC which acts as selective and differential medium. Only the typical sorbitol negative colonies were considered as positive for $E$. coli $\mathrm{O} 157: \mathrm{H} 7$. Many other researchers have used CT-SMAC agar as a selective medium for the isolation of $E$. coli $\mathrm{O} 157: \mathrm{H} 7$. Bindu and Krishnaiah (2010) tested 250 samples collected from various sources for the presence of $E$. coli $\mathrm{O} 157: \mathrm{H} 7$ by employing cultural isolation on CT-SMAC agar and reported that only 11 samples were positive by cultural methods. Similarly Aseel et al., (2013) used CT-SMAC agar for isolation of $E$. coli $\mathrm{O} 157: \mathrm{H} 7$ strain from fecal samples of zoo animal with satisfactory results. The isolated sorbitol negative colonies were further subjected for Gram's staining, where in the suspected E. coli O157:H7 isolates took counter stain and seen as pink coloured coccobacilli. Further, when inoculated on EMB agar as differential media, the suspected E. coli $\mathrm{O} 157: \mathrm{H} 7$ isolates produced black centered colonies with metallic sheen and were presumed to be positive for $E$. coli O157:H7.

Based on the cultural isolation method, per cent animals that showed shedding of $E$. coli O157:H7 was 7.73 in sheep and 6.00 in goats. The results obtained in this study are in correlation with Wani et al., (2003), Oporto et al., (2008), Mersha et al., (2010) and Akanbi et al., (2011).

Conventional culture methods are very useful for the identification of $E$. coli O157:H7. However, these methods are time consuming (Arthur et al., 2005) and there is a possibility to get false positive results (Orth et al., 2009) as supported by the present findings for identification of $E$. coli $\mathrm{O} 157: \mathrm{H} 7$.

Fig.1 CT-SMAC agar plate showing Sorbitol negative colonies (White coloured) indicating positive for E. coli $\mathrm{O} 157: \mathrm{H7}$ 


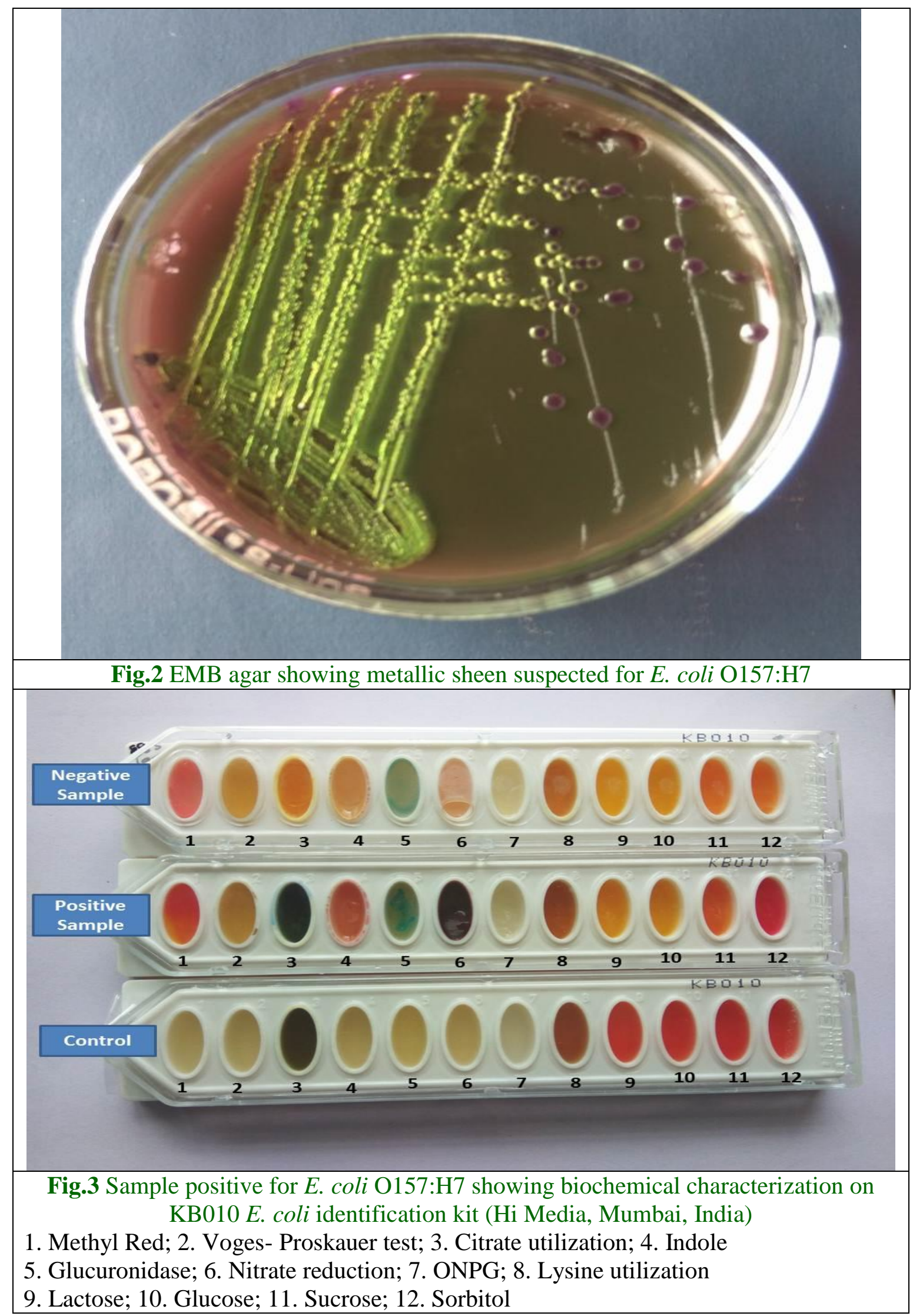




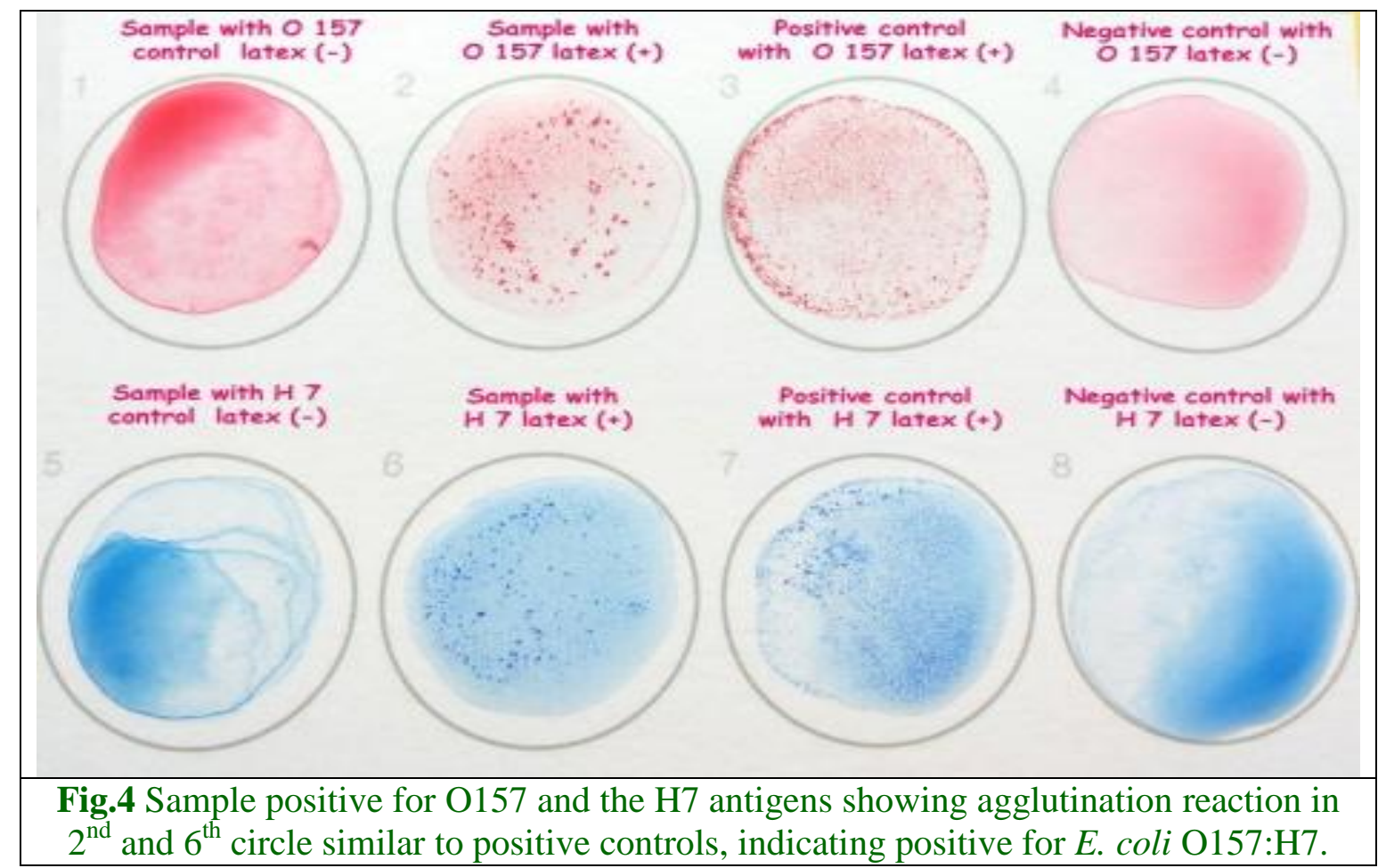

Table.1 Identification of E. coli $\mathrm{O} 157: \mathrm{H} 7$ in the faecal samples of sheep and goats by using different diagnostic methods

\begin{tabular}{|l|c|c|c|c|c|c|}
\hline \multicolumn{1}{|c|}{$\begin{array}{c}\text { Diagnostic test/ } \\
\text { Species }\end{array}$} & Positive & Negative & $\begin{array}{c}\text { Per cent } \\
\text { positive } \\
(\%)\end{array}$ & Positive & Negative & $\begin{array}{c}\text { Per cent } \\
\text { positive } \\
(\%)\end{array}$ \\
\hline $\begin{array}{l}\text { Cultural } \\
\text { identification }\end{array}$ & 40 & 477 & $\mathbf{7 . 7 3}$ & 27 & 423 & $\mathbf{6 . 0 0}$ \\
\hline $\begin{array}{l}\text { Biochemical } \\
\text { Characterisation }\end{array}$ & 25 & 492 & $\mathbf{4 . 8 3}$ & 16 & 434 & $\mathbf{3 . 7 7}$ \\
\hline $\begin{array}{l}\text { Latex agglutination } \\
\text { test }\end{array}$ & 19 & 498 & $\mathbf{3 . 6 7}$ & 13 & 437 & $\mathbf{2 . 8 8}$ \\
\hline
\end{tabular}

As such there are no differences in the biochemical characters between $E$. coli O157:H7 and other serotypes of $E$. coli except for sorbitol fermentation. E. coli $\mathrm{O} 157: \mathrm{H} 7$ is sorbitol negative and other serotypes are sorbitol positive (Bettelheim, 2007).

The present study revealed $4.83 \%$ of sheep and $3.77 \%$ of goats as shedders of E. coli O157:H7 based on the identification by biochemical characters. Similar results on biochemical tests were obtained by many researchers for detection of E. coli $\mathrm{O} 157: \mathrm{H} 7$ (Bindu and Krishnaiah, 2010; Faten and Afaf, 2013; Adamu et al., 2014).

However, biochemical reactions alone cannot differentiate between E. coli O157:H7 and other serotypes of E. coli (Bettelheim, 2007). Strockbine et al., (1998) mentioned Escherichia hermanii is biochemically similar to E. coli $\mathrm{O} 157: \mathrm{H} 7$ and can produce sorbitol 
negative colonies on CT-SMAC indicating the chances of getting false positive samples. In this context latex agglutination test (Wellcolex® E. coli $\mathrm{O} 157: \mathrm{H7}$ ) was used in this study for the confirmative identification of $E$. coli $\mathrm{O} 157: \mathrm{H} 7$ by detecting presence of the $\mathrm{O} 157$ and the $\mathrm{H} 7$ antigens. The isolates positive for $\mathrm{O} 157$ and the $\mathrm{H} 7$ antigens showed agglutination reaction with latex coated with respective monoclonal antibodies. Since monoclonal antibodies react very specifically with their respective antigens, latex agglutination test was used for the confirmation of the isolates as $E$. coli O157:H7. USDA FSIS recommends use of latex agglutination test for the confirmation of E. coli $\mathrm{O} 157: \mathrm{H} 7$ from meat products and environmental samples (USDA FSIS, 2015).

Based on the results of latex agglutination test $3.67 \%$ of the sheep samples and $2.88 \%$ of the goats samples showed shedding of $E$. coli O157:H7. Similar type of results was also noticed by many researchers using latex agglutination test for the confirmation of $E$. coli O157:H7 isolates (Mohmmed et al., 2012; Divya et al., 2013 and Faten and Afaf, 2013).

The results of cultural isolation, biochemical Characterisation and Latex agglutination test of $E$. coli $\mathrm{O} 157: \mathrm{H} 7$ from faecal samples of sheep and goats are presented in Table 1 .

Out of the total faecal samples tested in the present study, per cent of shedding of $E$. coli O157:H7 in sheep was found to be $3.67 \%$ (19 out of 517 samples) and $2.88 \%$ in goats (13 out of 450 samples). So the percentage of sheep showing shedding of E. coli $\mathrm{O} 157: \mathrm{H} 7$ in faeces was higher $(3.67 \%)$ than goats (only $2.88 \%$ ). These findings indicated that, though sheep and goats are considered as reservoir for E. coli O157:H7 (Ogden et al., 2005; Novotna et al., 2005; Mersha et al., 2010 and Yilmaz, 2014), sheep are more likely to shed this zoonotic pathogen than goats. These results are in accord with the results obtained by Mersha et al., (2010), Akanbi et al., (2011) and Soderlund et al., (2012). But the results are on contrary with Rey et al., 2006. The differences in host response and excretion dynamics could be the reason for such a vast gap in shedding of this pathogen between sheep and goats. There could be differences in the innate immune response among the two species that negates bacterial replication on the epithelium and either reduces attachment to or increases detachment from the epithelium of the terminal rectum (Mersha et al., 2010).

\section{References}

Adamu, M. T., Shamsul, B. M. T., Desa, M. N. and Khairani-Bejo, S., 2014. A review on Escherichia coli O157:H7-The Super Pathogen. Health Environ. J., 5 (2): 78-93

Akanbi, B. O., Mbah, I. P. and Kerry, P., C., 2011. Prevalence of Escherichia coli O157:H7 on hides and faeces of ruminants at slaughter in two major abattoirs in Nigeria. Lett. Appl. Microbiol., 53(3): 336-40

Arthur, T. M., Bosilevac, J. M., Nou, X. and Koohmaraie, M., 2005. Evaluataion of culture and PCR based detection methods for $E$. coli O157: $\mathrm{H} 7$ in ground beef. $J$. Food Prot., 68: 1566-1574

Aseel, M. H., Aseel, M. H. and Jenan, M. K., 2013. Isolation of Escherichia coli O157:H7 strain from fecal samples of zoo animal. The Sci. World J., 1-5

Bach, S. J., Mcallister, T. A., Veira, D. M., Gannon, V. P. J. and Holley, R. A., 2002. Transmission and control of Escherichia coli O157: H7 - A review. Can. J. Anim. Sci., 82(4):475-490

Bettelheim, K. A., 2007. The non-O157 Shigatoxigenic

(Verocytotoxigenic) Escherichia coli; under-rated pathogen. Crit. Rev. Microbiol., 33: 67-87

Bindu Kiranmayi, C. H. and Krishnaiah N., 2010. Detection of Escherichia coli 
O157:H7 prevelance in foods of animal origin by cultural methods and PCR technique. Vet, World, 3 (1): 13-16

Blanco, J., Blanco, M., Blanco, J. E., Mora, A., Gonzalez, E. A., Bernardez, M. I., Alonso, M. P., Coira, A., Rodriguez, A., Rey, J., Alonso, J. M. and Usera, M. A., 2003. Verotoxin-producing Escherichia coli in Spain: Prevalence, serotypes, and virulence genes of 0157:H7 and nonO157 VTEC in ruminants, raw beef products, and humans. J. Exp. Biol. Med., 228: $345-351$

Centers for disease control and prevention (CDC) 2009. Multistate outbreak of $E$. coli $\mathrm{O} 157: \mathrm{H} 7$ infections linked to eating raw refrigerated, prepackaged cookie dough. Update June 30, 2009

Divya, S. M., Masilamani, S. and Manohar, P. W., 2013. Prevalence, Antimicrobial Resistance Profiles and Molecular Characterization of Escherichia coli O157:H7 in a Metropolitan City of India. $2^{\text {nd }}$ International Conference on Chemical, Environmental and Biological Sciences (ICCEBS), March 17-18, Dubai (UAE), pp. 21-23

Faten, A. A., Al-Dawmy and Afaf, Abdulrahman, Y., 2013. Prevalence of E.coli $0157: H 7$ in intestinal and Urinary tract infection in children. Int. J.Adv. Res., 1(8): 111-120

Hazarika, R. A., Singh, D. K., Kapoor, K. N., Agarwal, R. K., Padey, A. B. and Purusottam., 2007. Verotoxic E.coli (STEC) from beef and its products. Indian J. Exp. Biol., 45: 207-211

Jo, P. M. Y., Kim, J. H., Lim, J.H., Kang, M. Y., Koh, H. B. and Park, Y. H., 2004. Prevalence of characteristics of Escherichia coli $\mathrm{O} 157$ from major food animals in Korea. Int. J. Food Microbiol., 95: 41-49

Khan, A., Das, S. C., Ramamurthy, T., Sikdar, A., Khanam, J., Yamasaki, S., Takeda, Y. and Nair, G. B., 2002a. Antibiotic resistance, virulence gene, and molecular profiles of Shiga toxin-producing Escherichia coli isolates from diverse sources in Calcutta, India. J. Clin. Microbiol., 40: 2009-2015

Khan, A., Yamasaki, S., Sato, T., Ramamurthy, T., Pal, A., Datta, S., Chowdhury, N. R., Das, S. C., Sikdar, A., Tsukamoto, T., Bhattacharya, S. K., Takeda, Y. and Nair. G. B., 2002b. Prevalence and genetic profiling of virulence determinants of non-O157 Shiga toxin-producing Escherichia coli isolated from cattle, beef, and humans, Calcutta, India. Emerg. Infect. Dis., 8: 54-62

La Ragione, R. M., Best, A., Woodward, M. J. and Wales, A. D., 2009. Escherichia coli O157:H7 colonization in small domestic ruminants. FEMS Microbiol. Rev., 33: 394-410

Mersha, G., Asrat, D., Zewde, B. M. and Kyule, M., 2010. Occurrence of E. coli O157:H7 in faeces, skin and carcasses from sheep and goats in Ethiopia. Lett. Appl. Microbiol., 50(1): 71-76

Mohmmed, H. K., Awatif, H. I. and Farooq, L. J., 2012. Detection of $\mathrm{rbO} 157$ and fliCH7 Genes in E. coli isolated from Human and Sheep in Basrah Province. Raf. J. Sci., 23(1): 19-33

Narvaez-Bravo, C., Miller, M., Jackson, F. T., Jackson, S., Rodas-Gonzalez, A., Pond, K., Echeverry, A. and Brashears, M. M., 2013. Salmonella and Escherichia coli O157:H7 prevalence in cattle and on carcasses in a vertically integrated feedlot and harvest Plant in Mexico. J. Food Prot., 76(5): 786-795

Novotna, R., Alexa, P., Hamrik, J., Madanat, A., Smola, J. and Cizek, J., 2005. Isolation and characterization of shiga toxin- producing Escherechia coli from sheeps and goats from Jordan with evidence of multiresistant serotype O157:H7. Vet. Med. Czech., 50(3): 111118

Ogden, I. D., Macrae, M. and Strachan, N. J. C., 2005. Concentration and prevalence of Escherichia coli 0157:H7 in sheep faeces at pasture in Scotland. J. Appl. Microbiol., 98: 646-651 
Oporto, B., Esteban, J. I., Aduriz, G., Juste, R. A. and Hurtado, A., 2008. Escherichia coli $\mathrm{O} 157: \mathrm{H} 7$ and non-O157 Shiga toxinproducing $E$. coli in healthy cattle, sheep and swine herds in Northern Spain. Zoonoses Public Health, 55(2): 73-81

Orth, D., Grif, K., Khan, A. B., Naim, A., Dierich, M. P. and Wurzner, R., 2007. The Shiga toxin genotype rather than the amount of Shiga toxin or the cytotoxicity of Shiga toxin in vitro correlates with the appearance of the hemolytic uremic syndrome. Diagn. Microbiol. Infect. Dis., 59: 235-242

Orth, D., Grif, K., ZImmerhackl, L. B. and Wurzner, R., 2009. Sorbitol-fermenting Shiga toxin-producing Escherichia coli O157 in Austria. Wien. Klin. Wochenschr., 121: 108-112

Pradeep Kumar, 2017. Molecular epidemiological study on shedding pattern of E.coli $\mathrm{O} 157: \mathrm{H} 7$ with respect to species, breed, age and season. $\mathrm{Ph} \mathrm{D}$ thesis submitted to P. V. Narsimha Rao Telangana Veterinary University, Rajendra Nagar, Hyderabad, India

Puttalingamma, V. S. N. and Harshvardhan, B., 2013. Detection of E. coli serovar O157:H7 by simultaneous amplification of chuA, ehxA, espP, stxl, and wzygenes from food samples using multiplex PCR format. Inte. J. Res.Biol. Sci., 3(4):157160

Rey, J., Sanchez, S., Blanco, J. E., Hermoso, D. E., Mendoza, J., Hermoso, D. E., Mendoza, M., Garcia, A., Gil, C., Tejero, N., Rubio, R. and Alonso, J. M., 2006. Prevalence, serotypes and virulence genes of Shiga toxin-producing Escherichia coli isolated from ovine and caprine milk and other dairy products in Spain. Int. J. Food Microbiol., 107: 212-217

Soderlund, R., Hedenström, I., Nilsson, A., Eriksson, E. and Aspán, A., 2012. Genetically similar strains of Escherichia coli $\mathrm{O} 157: \mathrm{H} 7$ isolated from sheep, cattle and human patients. BMC Vet. Res., 8: 200

Strockbine, N., Wells, J., Bopp, C. and Barrett, T., 1998. Overview of detection and sub typing methods. In Kapare, J., O'Brien, A. (Eds), Escherichia coli $\mathrm{O} 157: \mathrm{H} 7$ and other shiga toxin producing $E$. coli strains. American Society for Microbiology, Washington, DC. Pp. 331355

USDA-FSIS, 2015. Laboratory Guidebook; Detection, isolation and identification of Escherichia coli 0157:H7 from meat products and carcass and environmental sponges. Available at: http://www.fsis.usda.gov. Accessed on January 2016.

Wani, S. A., Bhat, M. A., Samanta, I., Nishikawa, Y. and Buchh, A. S., 2003. Isolation and characterization of Shiga toxin -producing E. coli (STEC) and enteropathogenic $E$. coli (EPEC) from calves and lambs with diarrhoea in India. Lett. Appl. Microbiol., 37: 121-126

Wani, S. A., Pandit, F., Samanta, I., Bhat, M. A. and Buchh, A. S., 2004. Molecular epidemiology of Shiga-toxin producing Escherichia coli in India. Curr. Sci., 87: $1345-1353$

Yilmaz , 2014. Sheep as an important source of E. coli $\mathrm{O} 157 / \mathrm{O} 157: \mathrm{H} 7$ in Turkey. Vet. Microbiol., 172(3-4): 590-595

\section{How to cite this article:}

Pralhad, Basavaraj Awati, B.K. Ramesh, N.A. Patil, Pradeep Kumar, B. Jaganath Rao, P.T. Vinay, K.C. Mallinath, Arun Kharate, P. Suryakanth and Revappayya, M. 2018. Occurrence of Escherichia coli O157:H7 in Faecal Sample of Sheep and Goats in North East Karnataka. Int.J.Curr.Microbiol.App.Sci. 7(12): 242-250. doi: https://doi.org/10.20546/ijcmas.2018.712.030 